\title{
Counting the cost
}

In last month's issue of The Journal of Laryngology \& Otology, our principle review article outlined the work of the National Institute for Health and Clinical Excellence (NICE) in the UK in respect of otolaryngology. ${ }^{1}$ The review article by Hamilton and colleagues in the present issue takes this topic one step further by considering cost-utility analysis as a method of decision-making in healthcare, and otolaryngology in particular. ${ }^{2}$ As they explain in their article, 'utility value' is used as a measure of the strength of an individual's preference for a particular health state. This instrument is recognised by organisations such as NICE as the optimum method of assessing cost-effectiveness. In this way, potential improvements in quality of life resulting from treatment can be compared across many differing medical conditions.

The 'sandwich' articles in the Journal's content are the 'Short Communications'. These offer authors the opportunity to document in a brief way new treatments and practical surgical tips. The Editors welcome this type of article, as they are highly valued by otolaryngologists in practice. In this issue, there are three such articles covering wide-ranging topics. Amin and colleagues describe the first reported use of laser tympanic plexus ablation for first bite syndrome, a rare but debilitating condition characterised by severe facial pain brought on by the first bite of each meal. ${ }^{3}$ Loizou and colleagues tackle the difficult issue of neonatal and infant laryngeal endoscopy, and discuss methods in which infants can be 'pacified' to facilitate optimum visualisation of the larynx. ${ }^{4}$

Another 'first' in terms of medical treatment to be reported in this issue concerns the difficult condition of patulous eustachian tube. Rodrigues and colleagues describe the use of a suspension implant inserted by a computed tomography guided, trans-cutaneous method. ${ }^{5}$ The patient achieved prompt symptomatic relief and remained symptom-free after six months. Finally, the development of robotic thyroid surgery techniques are considered by Wang and $\mathrm{Wu}{ }^{6}$ They describe how, using robotic thyroidectomy methods, it is possible to dissect along the thyroid capsule and identify a non-recurrent inferior laryngeal nerve. They emphasise the importance of proper knowledge of radiological and surgical anatomy.

\section{ROBIN YOUNGS EDWARD FISHER Editors}

\section{References}

1 Aval S, Pabla L, Flood LM. The National Institute for Health and Clinical Excellence, and otolaryngology: review of the evidence. $J$ Laryngol Otol 2014;128:2-12

2 Hamilton D, Hulme C, Flood L, Powell S. Cost-utility analysis and otolaryngology. J Laryngol Otol 2014;128:112-8

3 Amin N, Pelser A, Weighill J. First bite syndrome: our experience of laser tympanic plexus ablation. J Laryngol Otol 2014;128: 166-8

4 Loizou P, Haloob N, Evgeniou E. Per-oral flexible laryngoscopy in awake neonates and infants: the 'pacifier' technique. J Laryngol Otol 2014;128:169-70

5 Rodrigues JCL, Waddell A, Cook J-L. A novel, computed tomography guided, trans-cutaneous approach to treat refractory autophony in a patient with a patulous eustachian tube. J Laryngol Otol 2014;128: $182-4$

6 Wang C-C, Wu C-H. Non-recurrent inferior laryngeal nerve identification during robotic thyroidectomy. J Laryngol Otol 2014; 128:199-202 